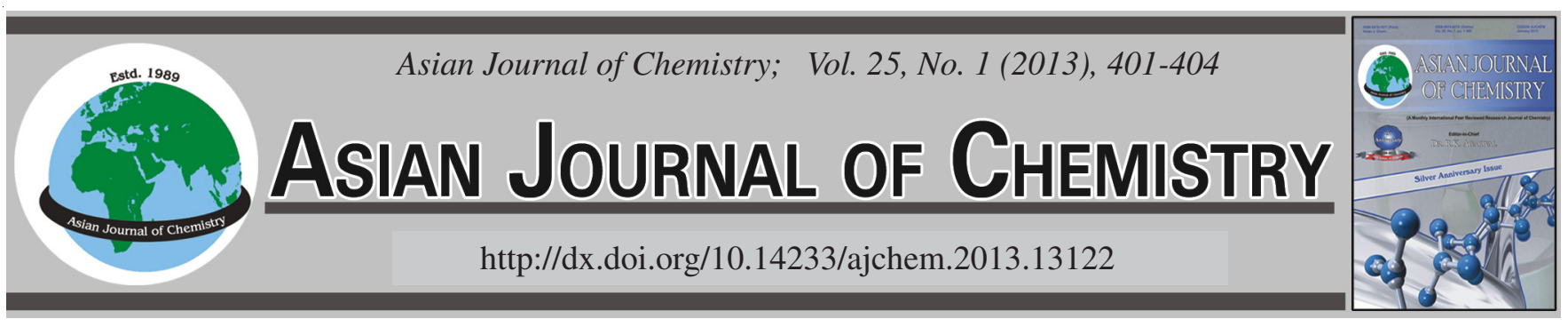

\title{
Preparation and Characterization of Cube-Like Magnesium Hydroxide by Gaseous Ammonia Bubbling
}

\author{
Xue Li, Tianbo Fan and Yunyi Liu* \\ College of Chemical Engineering, Shenyang University of Chemical Technology, Shenyang 110142, P.R. China \\ *Corresponding author: Tel: +86248938 3902; E-mail: 1xltm@ @otmail.com
}

Cube-like magnesium hydroxide nanoparticles were synthesized by ammonia gas $\left(\mathrm{NH}_{3}\right)$ bubbling in the magnesium chloride $(\mathrm{MgCl})$ solution. The whole preparation did not require any modification such as hydrothermal treatment or surfactants. X-ray diffraction, scanning electron microscopy, laser particle size analyzer and thermo-gravimetric analyses have been employed to characterize these products. The | influence of synthesis parameters on the magnesium hydroxide was investigated,such as types of base precipitants, reaction time and temperature. The growth mechanisms of magnesium hydroxide were also discussed.

Key Words: Characterization, Magnesium hydroxide, Flame retardant.

\section{INTRODUCTION}

Inorganic compound magnesium hydroxide as a smokingand toxic-free additive has been extensively used in halogenfree flame-retardant polymeric materials. However, its fatal disadvantages are low flame-retardant efficiency and thus very large usage amount, which lead the mechanical properties of a flame-retardant polymeric material to drop down sharply. The surface modification of magnesium hydroxide in order to increase the compatibility between magnesium hydroxide particles and polyolefin can enhance the performance of composites. Unfortunately, the enhancement is so slight that the composites are still far away from their applications. Nanosized magnesium hydroxide has a possibility to solve the above problems because of the mechanical and flameretardant reinforcing functions of nanosized composite materials $^{1-5}$.

Nanosized magnesium hydroxide crystalline belongs to the hexagonal system, possessing an advantageous arrangement for the formation of platelet like crystals. Magnesium hydroxide may adopt different morphologies and sizes which in turn play critical roles in determining their different chemical and physical properties. These can be realized by several chemical processes. For examples, the flower-, needle- and rod-shaped particles were synthesized by precipitation reaction of a magnesium salt and an alkaline solution. While the lamellar- and the tube-shaped magnesium hydroxide could be prepared through hydrothermal reactions. According to literature reports ${ }^{6-15}$, microwave-assisted synthesis, pulsed laser ablation of $\mathrm{Mg}$, electrolysis of an aqueous magnesium salt solution, the hydrothermal reaction of magnesium oxide could also be used to control magnesium hydroxide particle sizes and shapes. All of these dealt with the crystallization, growth and aggregation behaviours of magnesium hydroxide crystals.

Compared with ammonia water and caustic soda as precipitant, the magnesium hydroxide prepared with gaseous ammonia has high purity and easy to filter. In present work, well-defined cubic magnesium hydroxide nanoparticles were firstly synthesized by ammonia bubbling method, blowing $\mathrm{NH}_{3}$ into $\mathrm{MgCl}_{2}$ solution without any modification such as hydrothermal treatment or surfactants. The objective of this paper is to investigate how to influence the magnesium hydroxide particle size, shape and agglomeration in $\mathrm{NH}_{3}$ bubbling reactors. In addition, the obtained magnesium hydroxide was analyzed with XRD, SEM,TG-DTA and laser particle size analyzer to determine its morphology and crystal structure.

\section{EXPERIMENTAL}

Preparation of magnesium hydroxide: The samples were obtained by precipitation, at a controlled temperature $20{ }^{\circ} \mathrm{C}$ $90^{\circ} \mathrm{C}$, of $200 \mathrm{~mL}$ magnesium salt solution of concentration 1 $\mathrm{mol} / \mathrm{L}$, by addition of $\mathrm{NH}_{3}$ flux $195 \mathrm{~mL} / \mathrm{min}$. Vigorous stirring $500 \mathrm{rpm}$ was applied during the $\mathrm{NH}_{3}$ bubbling. The suspension was kept at $105^{\circ} \mathrm{C}$ for $2 \mathrm{~h}$. The resulting precipitates were removed from the solution, rinsed three times with deionized water and then, dried in a vacuum desiccator at $50{ }^{\circ} \mathrm{C}$ for $5 \mathrm{~h}$. 
Characterization of magnesium hydroxide: The morphology and elemental analysis of the magnesium hydroxide products were examined by scanning electron microcopy at acceleration voltage of $10 \mathrm{kV}$ (SEM, JSM-6360LV) and Xray diffraction (XRD, a Bruker $\mathrm{D}_{8}$ advance diffractometer, with $\mathrm{CuK}_{\alpha}$ radiation $\left.(\lambda=0.1540562 \mathrm{~nm})\right)$, respectively. Thermogravimetric analyzer (TGA, NETZSCH STA449C) was used to identify the thermal behaviour of the products. The sample was heated under air atmosphere from ambient to $700^{\circ} \mathrm{C}$ at a heating rate of $15^{\circ} \mathrm{C} \mathrm{min}{ }^{-1}$. The size distribution of magnesium hydroxide was characterized by laser particle size analyzer (BT-9300H, Dandong Baite Products Co. Ltd., China).

\section{RESULTS AND DISCUSSION}

XRD Analyses of magnesium hydroxide: Fig. 1 displays the XRD patterns of the sample 1 (at $75^{\circ} \mathrm{C}$ ) without surfactants in the preparation. No impurities have found in the diffraction, which was attributed to the pure $\mathrm{NH}_{3}$ as precipitant. The corresponding XRD pattern (Fig. 1) coincided well with the position and the relative intensities for the powder diffraction standards of magnesium hydroxide (ICDD 84-2164). Compa$\operatorname{ring} \mathrm{I}_{001} / \mathrm{I}_{101}$ ratios, it can be seen that the resultant magnesium hydroxide exhibited a higher crystallinity and $\mathrm{I}_{001} / \mathrm{I}_{101}$ ratio of 1.09 , which indicated a more pronounced orientation. The [001] polar property was more weak than [101] polar, which would decrease the internal stress and surface polarity of magnesium hydroxide resulting in the more stable structure of magnesium hydroxide.

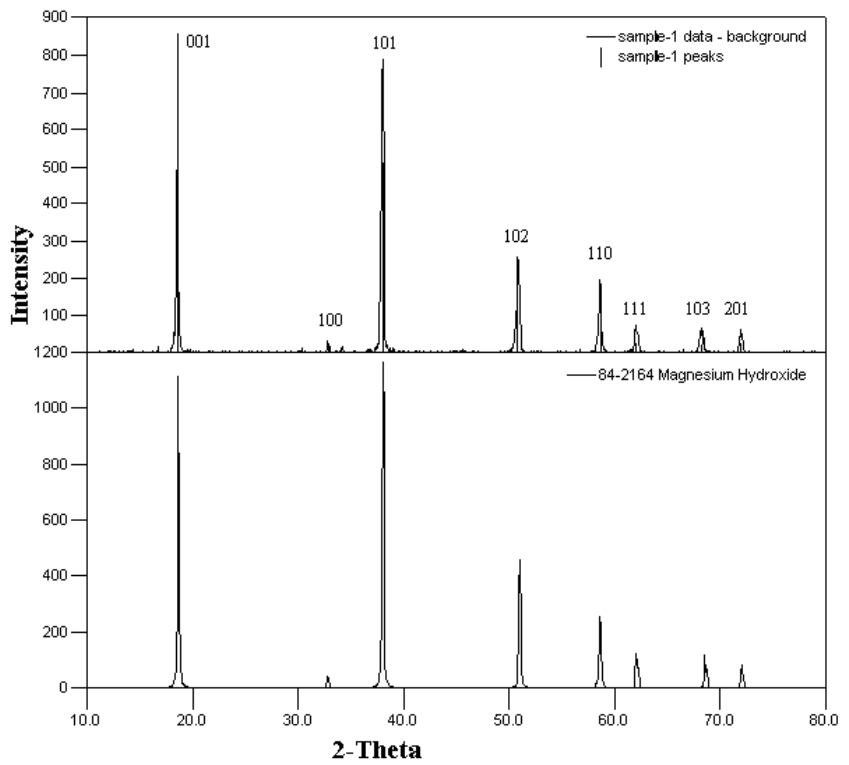

Fig. 1. XRD pattern of sample 1 and PDF2-2003 No.84-2164

TG-DTA analyses of magnesium hydroxide: TG-DTA technique in Fig. 2 was used to analyze the thermal behaviour of the sample 1 and thus could provide the necessary data for the following decomposition process. The decomposition temperature, which was the temperature at which maximum rate of weight loss occurs, was about $392.3^{\circ} \mathrm{C}$. The stage was ended at $570^{\circ} \mathrm{C}$, which was corresponded to the decomposition of the magnesium hydroxide, $\mathrm{Mg}(\mathrm{OH})_{2}=\mathrm{MgO}+\mathrm{H}_{2} \mathrm{O}$. The theoretical weight loss for the $\mathrm{Mg}(\mathrm{OH})_{2}-\mathrm{MgO}$ transformation was $30.8 \%$, which was slightly higher than the observed $30 \%$. We ascribed it to the incompleteness of the decomposition reaction in this temperature range. According to the DTA line, the thermal decomposition was obvious from $358.9^{\circ} \mathrm{C}$ to $395.9{ }^{\circ} \mathrm{C}$ with weight loss $25.2 \%$, which account for $81.6 \%$ in total weight loss. The maximum endothermic peak occurred at $392.3^{\circ} \mathrm{C}$.

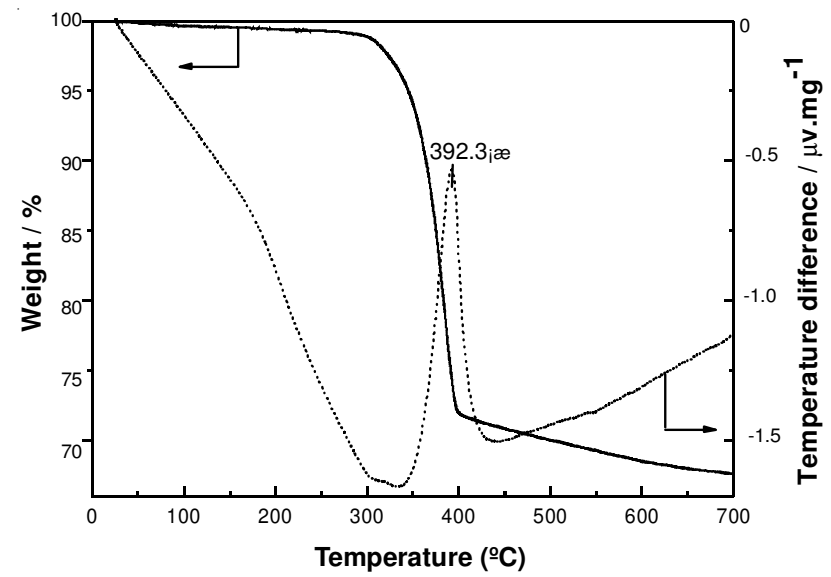

Fig. 2. TG-DTA curves of sample 1

Influence of reaction time: As shown in Fig. 3, when the reaction time was $1 \mathrm{~h}$ at $75^{\circ} \mathrm{C}$, magnesium hydroxide crystals took lamellar shape completely. Furthermore, the particles diameters size and thickness increased with the increase of reaction time. Considering the magnesium hydroxide yield and particle size, $2 \mathrm{~h}$ was applied in the following experiments.
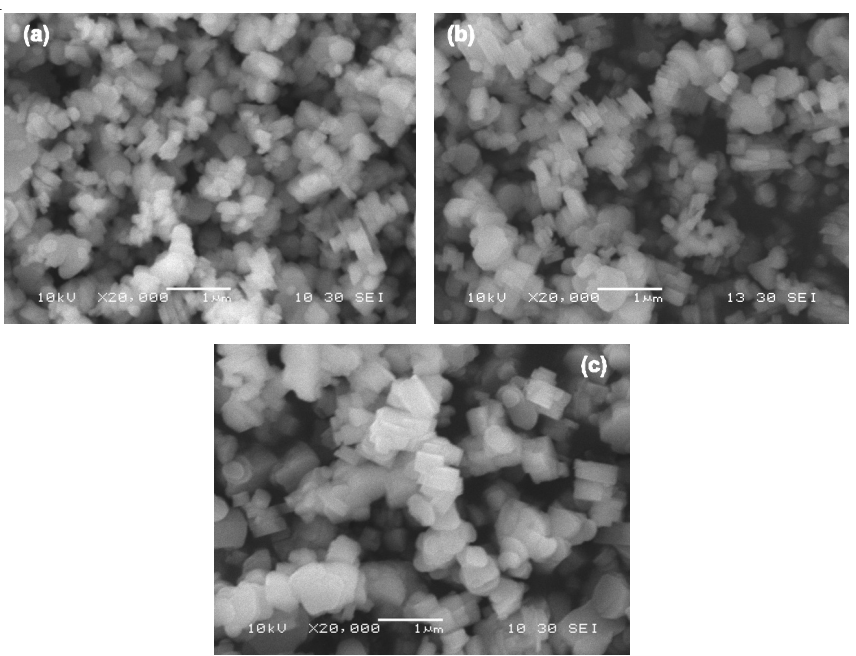

Fig. 3. SEM of magnesium hydroxide synthesized at different time (a-1h, b-2h-sample 1, c-4h)

\section{Influence of reaction temperature}

Particle size distribution of magnesium hydroxide: Fig. 4 shows the temperature effect on the particle size distribution. It was found that magnesium hydroxide size mostly decreased as increasing the reaction temperature. The mean particle size of sample 1 was $0.74 \mu \mathrm{m}$ at $75^{\circ} \mathrm{C}$. The result was better than other temperature.

SEM images of magnesium hydroxide: Fig. 5 shows the SEM images of magnesium hydroxide crystals obtained 
from the $1.0 \mathrm{~mol} / \mathrm{L} \mathrm{MgCl}_{2}$ solution at 20,40, 55, 75 and 90 ${ }^{\circ} \mathrm{C}$. Temperature exerted a strong influence on the resulting morphology and aggregation behaviour of the magnesium hydroxide particles.

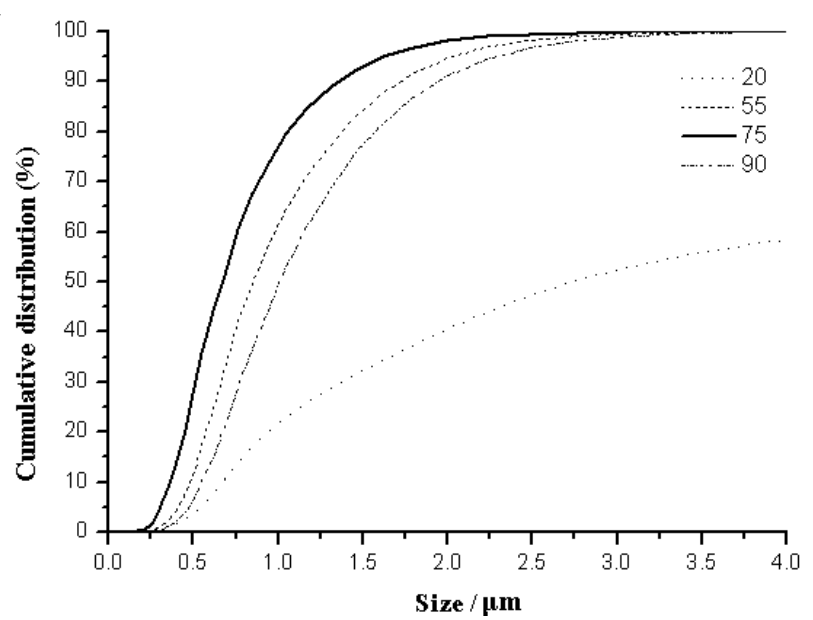

Fig. 4. Particle size distribution of magnesium hydroxide at different temperature $\left(20^{\circ} \mathrm{C}, 55^{\circ} \mathrm{C}, 75^{\circ} \mathrm{C}, 90^{\circ} \mathrm{C}\right)$

Fig. 5a, b exhibit a sunflower-shaped superstructure composed of magnesium hydroxide sheets and aggregated severely. Fig. 5c, d present the thinner lamellar shaped crystals. The obtained samples exhibited the same aggregation phenomenon
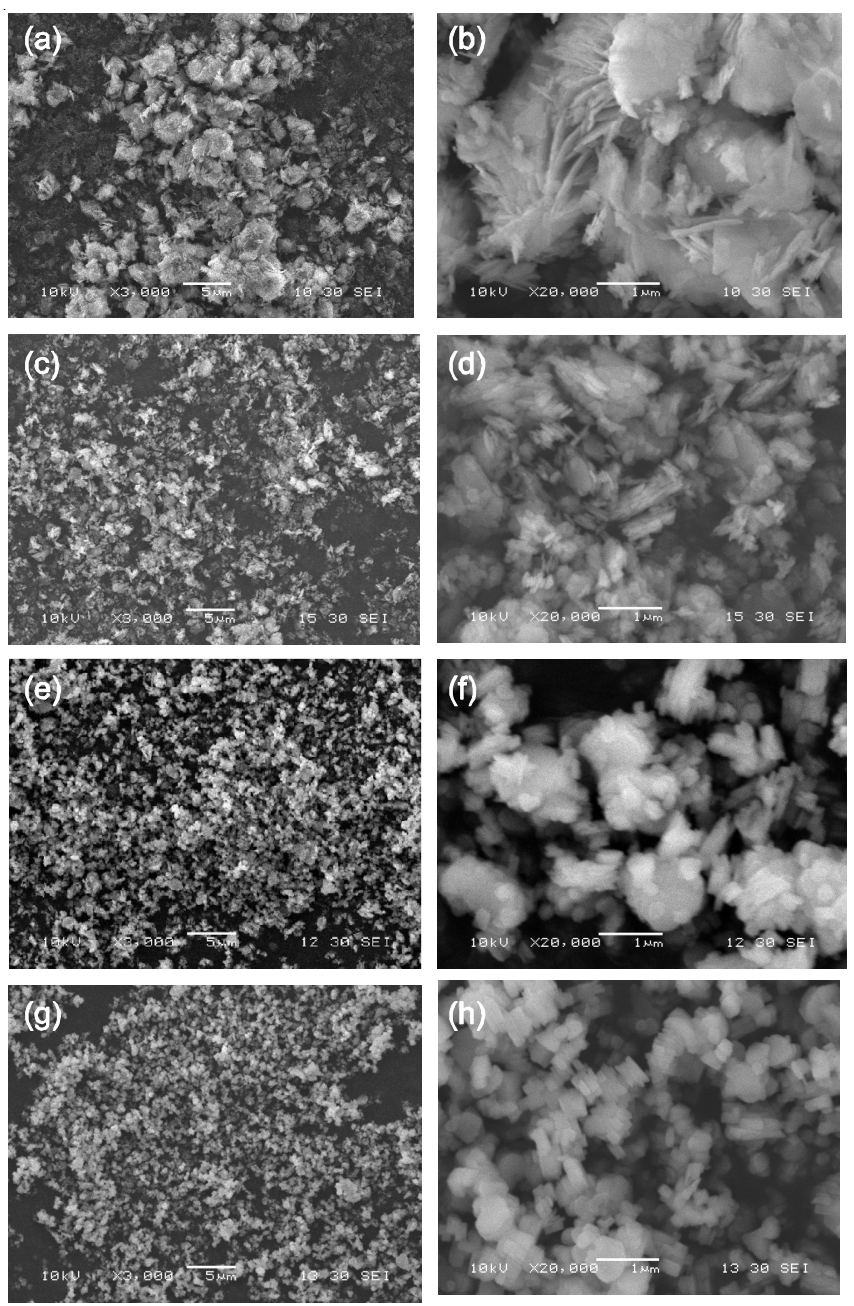
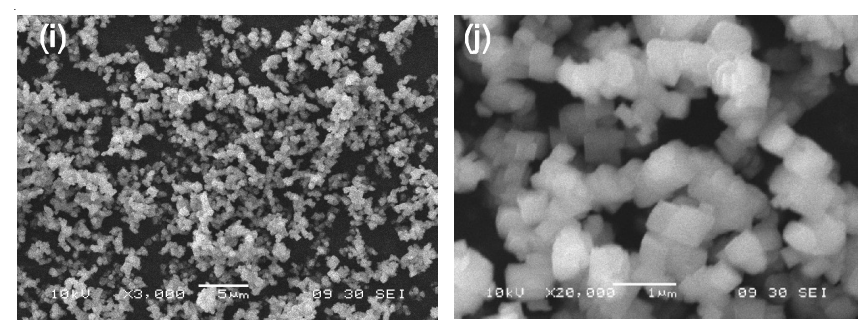

Fig. 5. SEM micrographs of magnesium hydroxide at different temperature (a, b- $20{ }^{\circ} \mathrm{C}, \mathrm{c}, \mathrm{d}-40{ }^{\circ} \mathrm{C}, \mathrm{e}, \mathrm{f}-55^{\circ} \mathrm{C}, \mathrm{g}, \mathrm{h}-75^{\circ} \mathrm{C}$-sample $1, \mathrm{i}, \mathrm{j}-90^{\circ} \mathrm{C}$ )

of magnesium hydroxide platelets. Fig. 5e, f also present the platelet-like crystals and their lamellar aggregates. The particle size distribution was improved and shape became more regular. While the synthesis at $75^{\circ} \mathrm{C}$ produced the typical cube-like' feature displayed in Fig. $5 \mathrm{~g}$, h. It can be clearly seen that the rough lamellar crystals have turned into the well-defined cubic morphology with perfectly smooth surface and narrow size distributions (D $50=0.74 \mathrm{~mm}$ ). When the temperature was controlled at $90{ }^{\circ} \mathrm{C}$, the magnesium hydroxide particle size increased and specific surface area decreased. Comparing the conditions above, the temperature had to be driven at $75^{\circ} \mathrm{C}$ in order to get desirable inflaming retarding products. It was to be emphasized that all the experiments and SEM pictures were conducted without dispersing agent, which presented the primitive shape. On a morphological point of view, the resulted samples experienced from irregular lamellar to the thick cubelike feature with the temperature increased.

Growth mechanism of magnesium hydroxide: By means of bubbling $\mathrm{NH}_{3}$ at the aqueous solutions could result in magnesium hydroxide with the sunflower-like structures at $20{ }^{\circ} \mathrm{C}$ and with the platelet-like crystals at $40{ }^{\circ} \mathrm{C}$ and with the cube-shaped superstructures at $75^{\circ} \mathrm{C}$. By the results listed above, the plausible formation process of cube-shaped magnesium hydroxide was schematically illustrated in the following.

Although the exact formation mechanism of these samples was still under investigation, it was obvious that surface energy places an important role. Bonding between particles could reduce total energy by removing surface energy associated with unsatisfied bonds. Generally, there were strongly bound water molecules on the surface of magnesium hydroxide colloids, because $\mathrm{Mg}^{2+}$ ion prefer binding to water. Thermodynamically, the primary driving force of growing magnesium hydroxide microspheres was to minimize the surface energy of magnesium hydroxide nanosheets by removing surface energy associated with unsatisfied bonds. Individual nanosheets tend to aggregate perpendicularly to their surface planes to decrease the surface energy by reducing exposed areas (Fig. 5a-f).

On the other hand, the supersaturation and the $\mathrm{pH}$ value of the solution played a significant role on the crystal growth. As shown in Fig. 6, after the fast nucleation of magnesium hydroxide, the slowly diffusing rate of $\mathrm{NH}_{3}$ had nearly no influence on the chemical reaction, because that, after $1 \mathrm{~h}$, the $\mathrm{pH}$ value of bulk phases was nearly constant in the continuous operation (about 9.9). This was apt to perform products with uniform morphology (Fig. 5g-j). The major chemical reactions in this buffer solution can be formulated as: 


$$
\begin{gathered}
\mathrm{NH}_{3}+\mathrm{H}_{2} \mathrm{O} \rightarrow \mathrm{NH}_{4} \mathrm{OH} ; \Delta \mathrm{H}=-34.5 \mathrm{~kJ} \mathrm{~mol}^{-1} \\
\mathrm{MgCl}_{2}+2 \mathrm{NH}_{4} \mathrm{OH} \rightarrow \mathrm{Mg}(\mathrm{OH})_{2} \downarrow+2 \mathrm{NH}_{4} \mathrm{Cl} ; \\
\Delta \mathrm{H}=-178.1 \mathrm{~kJ} \mathrm{~mol}^{-1}
\end{gathered}
$$

A large amount of $\mathrm{NH}_{4} \mathrm{Cl}$ in the solution resulted in the decrease of ionization rate of $\mathrm{NH}_{3} \cdot \mathrm{H}_{2} \mathrm{O}$, so the formation rate of $\mathrm{OH}^{-}$was decreased. This system offer a kind of subtle conditions that were similar to the homogeneous precipitation of $\mathrm{OH}^{-}$ions released from urea, which was chemically favourable to the self-assembly of magnesium hydroxide ${ }^{16}$.

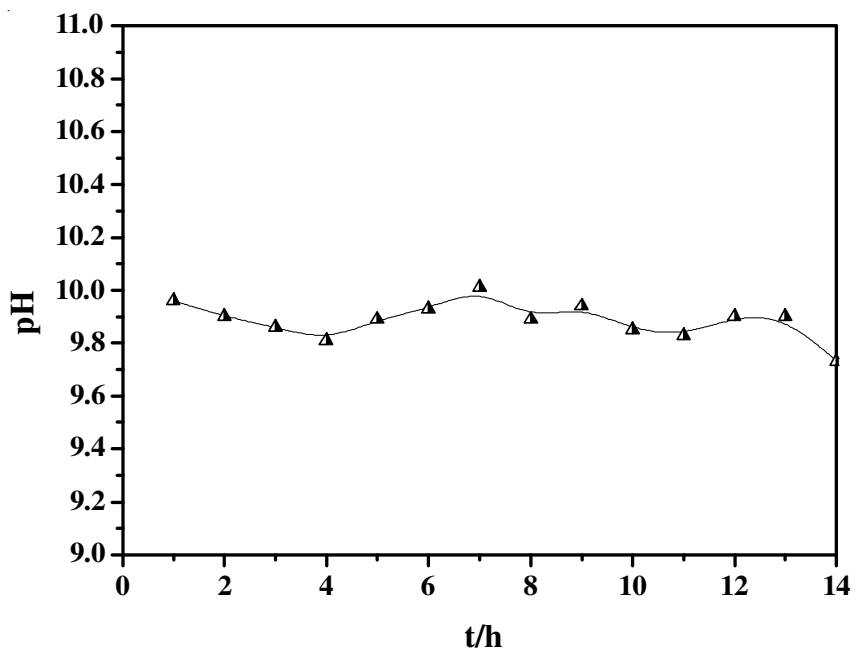

Fig. 6. $\mathrm{pH}$ of solution as a function of time

Furthermore, two factors may result in the formation of cube-like nanocrystals with the increase of temperature: (1) from the chemical reaction, it can be seen that an increase of temperature restrains the reaction rate for the exothermic reactions; and (2) the $\mathrm{NH}_{3}$ solubility in solution are strongly affected by the reaction temperature, which have the same effect on the $\mathrm{OH}^{-}$concentration. As seen in Fig. 7, solubility of ammonia in water decreased rapidly with the increase of temperature. At $20^{\circ} \mathrm{C}$, the $\mathrm{NH}_{3}$ solubility was about $33 \mathrm{~mol} / \mathrm{L}$ resulted in a high $\mathrm{OH}^{-}$concentration. There were numerous small particles, which provided many high-energy sites around $\operatorname{Mg}(\mathrm{OH})_{6}{ }^{4-17}$. The rapid speed of nucleation and severely aggregated magnesium hydroxide nuclei could result in poor crystalline (Fig. 5a,b). When the temperature was increased, the $\mathrm{NH}_{3}$ solubility rapidly decreased and the exothermic reaction was limited. The two factors directly resulted in the slow rate of the reaction. The nucleation progress was controlled and the crystal growth approach anisotropy. More important, the continuous feeding of magnesium atoms on the surface of spherelike microparticle could diffuse into two directions: circumferential diffusion and diffusion parallel to the tuber axis ([001]). It was the consequent supply of magnesium ions and the Ostwald ripening that caused sheets to become the relatively thick platelets. Finally, regular cube-like magnesium hydroxide particles were formed (Fig. $5 \mathrm{~g}$, h). As it is difficult to monitor the reaction once the system is sealed, quantities of work are needed to investigate the kinetics of the reaction.

\section{Conclusion}

In summary, cube-like magnesium hydroxide nanoparticles were firstly synthesized via a simple $\mathrm{NH}_{3}$ bubbling

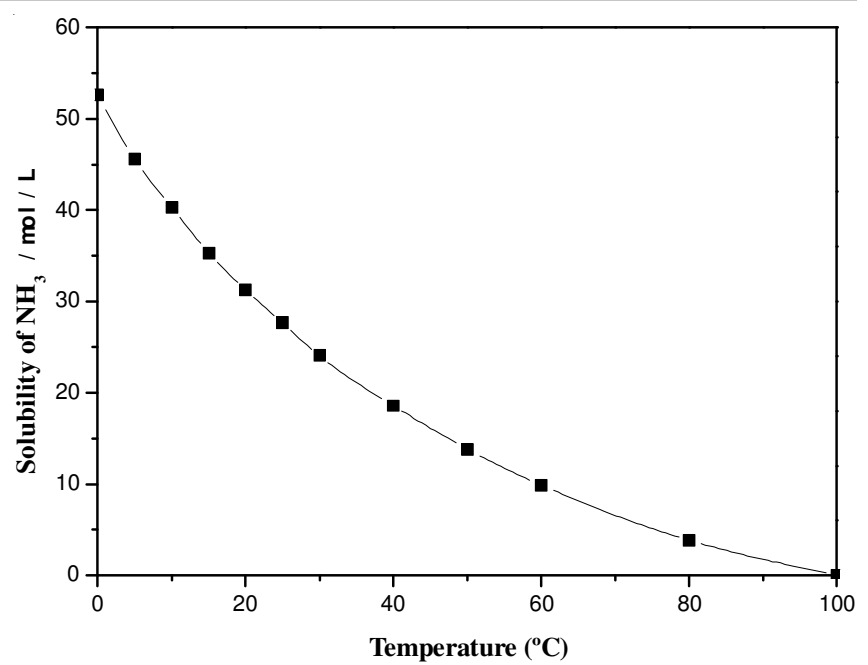

Fig. 7. Solubility of ammonia in water at atmosphere

process. The method did not require any surfactant, which would allow researchers to investigate the growth mechanism of the magnesium hydroxide nanoparticles in more natural conditions. The properties of the products were analyzed by XRD, FESEM, laser particle size analyzer, TG-DTA measurements. The resulted magnesium hydroxide was about 150$500 \mathrm{~nm}$ in mean particle size (D 50) and 100-200 nm in thickness. Interestingly, temperature exerted a strong influence on the resulting morphology and aggregation behaviour of the magnesium hydroxide particles. In comparison with conventional methods, the new approach is simple and more suitable for industrial scale production.

\section{REFERENCES}

1. H. Yan, X.H. Zhang, J.M. Wu, L.-Q. Wei, X.-G. Liu and B.-S. Xu, Powder Technol., 188, 128 (2008).

2. H. Gui, X.H. Zhang, Y.Q. Liu, W.F. Dong, Q.G. Wang, J.M. Gao, Z.H. Song, J.M. Lai and J.L. Qiao, Compos. Sci. Technol., 67, 974 (2007).

3. X.F. Wu, G.S. Hu, B.B. Wang and Y.-F. Yang, J. Cryst. Growth, 310, 457 (2008).

4. Z.Z. Li and B.J. Qu, Polym. Degrad. Stab., 81, 401 (2003).

5. J.C. Yu, A.W. Xu, L.Z. Zhang, R.Q. Song and L. Wu, J. Phys. Chem. B, 108, 64 (2004).

6. X. Li, G.B. Ma and Y.Y. Liu, Ind. Eng. Chem. Res., 48, 763 (2009).

7. C. Henrist, J.P. Mathieu, C. Vogels, A. Rulmont and R. Cloots, J. Cryst. Growth, 249, 321 (2003).

8. R. Giorgi, C. Bozzi, L.G. Dei, C. Gabbiani, B.W. Ninham and P. Baglion, Langmuir, 21, 8495 (2005).

9. C.Y. Tai, C.-T. Tai, M.-H. Chang and H.-S. Liu, Ind. Eng. Chem. Res., 46, 5536 (2007).

10. Y. Ding, G.T. Zhang, H. Wu, B. Hai, L.B. Wang and Y.T. Qian, Chem. Mater, 13, 435 (2001).

11. J.L. Booster, A.V. Sandwijk and M.A. Reuter, Miner. Eng., 16, 273 (2003).

12. J.M. Wu, Y. Hong, X.H. Zhang, L.Q. Wei, X.G. Liu and B.S. Xu, J. Colloid. Interf. Sci., 324, 167 (2008).

13. V.S. Shirure, A.S. Pore and V.G. Pangarkar, Ind. Eng. Chem. Res., 44, 5500 (2005).

14. D.M. An, L.L. Wang, Y.H. Zheng, S. Guan, X.Y. Gao, Y.M. Tian, H.X. Zhang, Z.C. Wang and Y.H. Liu, Colloid. Surf. A, 348, 9 (2009).

15. D.H. Chen, L.Y. Zhu, H.P. Zhang, K, Xu and M,C. Chen, Mater. Chem. Phys., 109, 224 (2008).

16. D.F. Xue, X.X. Yan and L. Wang, Powder Technol., 191, 98 (2009).

17. G.C. Xi, K. Xiong, Q.B. Zhao, R. Zhang, H.B. Zhang and Y.T. Qian, Cryst. Growth Des., 6, 577 (2006). 